\title{
Investigation and Experimental Measurement of Scissor Blade Cutting Forces Using Fiber Bragg Grating Sensors.
}

\author{
Dean Callaghan \\ Technological University Dublin, dean.callaghan@tudublin.ie \\ Ginu Rajan \\ Technological University Dublin \\ Mark McGrath \\ Technological University Dublin, mark.mcgrath@tudublin.ie
}

See next page for additional authors

Follow this and additional works at: https://arrow.tudublin.ie/engscheceart

Part of the Electrical and Electronics Commons

\section{Recommended Citation}

Callaghan, D. J., Rajan, G., McGrath, M. M., Coyle, E., Semenova, Y., Farrell, G. "Investigation and experimental measurement of scissor blade cutting forces using Fiber Bragg grating sensors". "Smart materials and structures" 20, 2011. doi:10.1088/0964-1726/20/10/105004

This Article is brought to you for free and open access by the School of Electrical and Electronic Engineering at ARROW@TU Dublin. It has been accepted for inclusion in Articles by an authorized administrator of ARROW@TU Dublin. For more information, please contact arrow.admin@tudublin.ie, aisling.coyne@tudublin.ie, gerard.connolly@tudublin.ie.

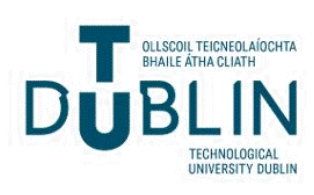




\section{Authors}

Dean Callaghan, Ginu Rajan, Mark McGrath, Eugene Coyle, Yuliya Semenova, and Gerald Farrell 


\title{
Investigation and experimental measurement of scissor blade cutting forces using fiber Bragg grating sensors
}

\section{J Callaghan ${ }^{1}$, G Rajan ${ }^{2}$, M M McGrath ${ }^{1}$, E Coyle $^{3}$, Y Semenova ${ }^{2}$ and G Farrell ${ }^{2}$}

${ }^{1}$ School of Manufacturing and Design Engineering, Dublin Institute of Technology, Bolton Street, Dublin 1, Ireland

${ }^{2}$ Photonics Research Centre, School of Electronic and Communications Engineering, Dublin Institute of Technology, Kevin Street, Dublin 8, Ireland

${ }^{3}$ School of Electrical Engineering Systems, Dublin Institute of Technology, Kevin Street, Dublin 8, Ireland

E-mail: dean.callaghan@dit.ie

Received 13 August 2010, in fina form 13 June 2011

Published

Online at stacks.iop.org/SMS/20/000000

\author{
(Abs. Ed: Emily) \\ Ascii/Word/SMS/ \\ sms365793/PAP \\ Printed 25/7/2011 \\ Spelling US \\ Issue no \\ Total pages \\ First page \\ Last page \\ File name \\ Date req \\ Artnum \\ Cover date
}

\begin{abstract}
This paper reports on unique and scalable sensorized medical scissor blades for application in minimally invasive robotic surgery. The blades exploit the strain sensing capabilities of a single fibe Bragg grating (FBG) sensor bonded to the blade surface. This smart sensing structure allows detection of friction and material fracture forces during cutting and subsequently enables accurate estimation of the blade kinetic friction coeff cient and fracture toughness values of the material being cut. We present theory on the determination of strain variation along the blade length during combined direct and lateral loading of the blade element during operation.

Demonstration of the sensorized instrument is realized on an application specif c experimental test-bed employing a commercial interrogation system for signal demodulation. Friction and cutting forces measured using the FBG are validated against load cell force data from the test-bed. Characterization tests showed that the sensorized blade has an unf ltered force sensing resolution of $0.5 \mathrm{~N}$ over a $30 \mathrm{~N}$ load range. This work demonstrates that a single optical f ber placed onto cutting instrument blades can, in an unobtrusive manner, reliably measure friction forces and material fracture properties during surgical cutting.
\end{abstract}

(Some f gures in this article are in colour only in the electronic version)

\section{Introduction}

Current commercially available minimally invasive robotic surgery (MIRS) systems greatly augment the surgeon's ability to carry out an operating procedure effectively but lack the facility to relay Haptic (kinesthetic and tactile) information to the user. This failure to provide for force measurement at the instrument end-effector restricts the effectiveness of MIRS systems in the detection of interaction forces during surgical tasks. A major obstacle in the provision of force feedback in MIRS systems is attributed to the actual measurement of the various interaction forces occurring at the instrument-tissue interface [1].
Research is ongoing into the use of strain/force sensors for the measurement of interaction forces at the instrument-tissue interface. Electrical resistive strain gauge (ERSG) technology has been utilized either in the form of a modular sensor [2, 3] or attached onto the instrument trocar [4-7]. These arrangements only measure interaction and bending forces on the trocar and do not measure grasping and cutting forces. One approach to overcoming this problem is the placement of strain/force sensing transducers either onto the instrument tip or as close as possible to it. Many research groups have indicated that the ideal location for force sensor placement is as close as possible to the site of interaction [2, 8-12], which for MIRS is at the instrument tip. This is technically the most challenging 


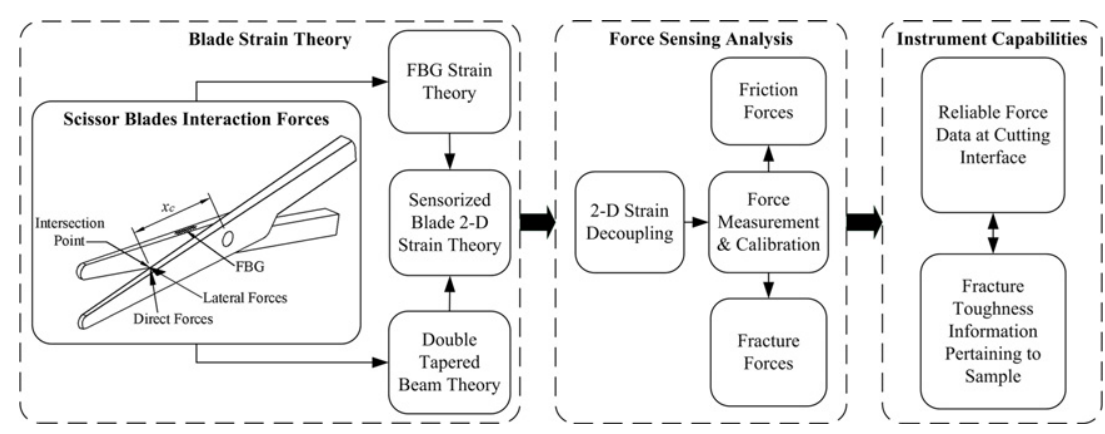

Figure 1. Proposed method of measuring blade-tissue interaction forces generated as a result of friction and material fracture properties.

location for placement of a force transducer owing to space limitations.

Our work focuses on the use of a particular type of optical sensor, an FBG, to address the aforementioned shortcomings of traditional sensing technologies. This alternative mode of sensing offers a number of additional advantages, including; compact dimensions, immunity from electromagnetic interference and multiplexing capabilities. Additionally a single f ber provides a low loss, high speed path for both tactile and force information to be transferred from the sensorized instrument to the remote robotic system [13].

Several groups are investigating the use of optical sensing techniques which facilitate the measurement of instrumenttissue force interactions in biomedical applications. Examples include the NeuroArm neurosurgical robotic system [14], a six degrees of freedom force-torque-sensor [15], a 2D f ber optic sensorized hook instrument for retinal surgery [16], and a sensorized surgical needle for use in a MRI environment [17]. These applications primarily consist of grasping, hooking and needle procedures. The work presented here investigates, both analytically and experimentally, the possibility of applying FBGs in surgical cutting applications.

The measurement of fracture toughness of soft tissues is also of interest to many researchers [18] particularly those involved in the development of reality-based tissue interaction models [19-21]. Fracture toughness is important when estimating or modeling interaction forces on surgical instruments during bisection, shearing and puncturing using scissors, blades and needles. Methods currently being employed to estimate the in vivo fracture toughness of biological tissue involve the use of material indentation or needle insertion $[22,23]$. Our proposed force sensing scheme allows detailed material fracture properties to be obtained during cutting.

The remainder of the paper is structured as follows; a description of the method employed to gather the interaction force information is presented in section 2 . The nature of the strains and forces which occur on the blade represented as a double tapered cantilever beam are discussed in section 3 . The experimental set-up and calibration of the sensorized prototype blade employing a surface mounted sensor are discussed in section 4. Experimental force and fracture toughness results from the sensorized prototype are presented in section 5, while conclusions resulting from the current work are discussed in section 6 .

\section{Blade-tissue interaction}

Inter-blade friction and the fracture properties of the material being cut are the primary factors affecting the magnitude of blade-tissue interaction forces. Our approach aims to integrate the sensor into the actual scissor blade at the bladetissue interaction site. This arrangement provides for excellent transmission of resulting blade strains to the sensor. This ensures that measurements are not negatively infl enced by factors such as mechanism friction and/or backlash. This increased accuracy provides the basis for improved analysis of the resultant force components.

Sharp dissection implies the use of concentrated energy on a relatively small area of tissue to achieve separation with little disruption to surrounding tissue. The scissor cutting method consists of two sharpened blades rotating about a common pivot location during closing. The blades are curved along their longitudinal axis such that, upon passing, there is a point contact between the cutting edges of both blades. This is the point at which all the external input energy, from scissor actuation, is concentrated. This point is referred to as the blade intersection point as shown in $\mathrm{f}$ gure 1 . This intersection point moves along the blade length as the included angle of the cutting edges changes through a cutting cycle. As a result, two coincident friction force components (direct and lateral) are occurring at the intersection point as it moves through the cycle. Implementing an FBG sensing element as part of the blade structure means that both the lateral and direct force components are measured simultaneously. However, it is the direct loading forces that are of primary interest in this work as they are the forces acting perpendicular to the blade cutting edges, giving a sense of feeling to the user. The approach taken in the development of a set of sensorized scissor blades capable of facilitating the measurement of these direct forces is shown in $\mathrm{f}$ gure 1 .

\section{Blade strain theory}

The nature and magnitude of strains at the FBG location resulting from direct and lateral force loading can be modeled analytically using elementary beam bending theory. This analysis provides the basis for blade calibration along its length and subsequent measurement of force information over the blade length during a cutting cycle. 


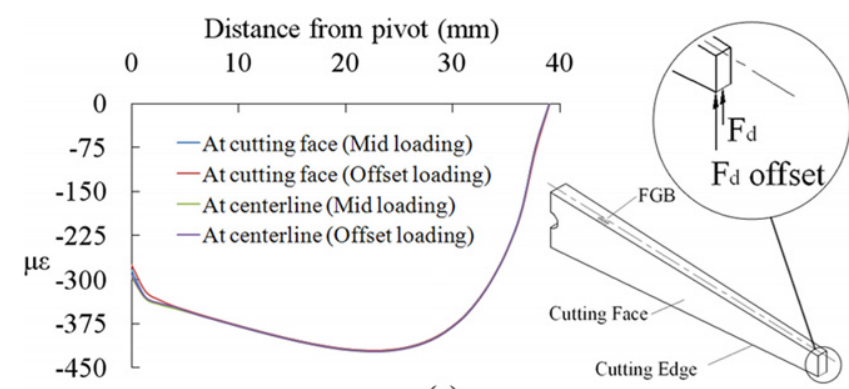

(a)

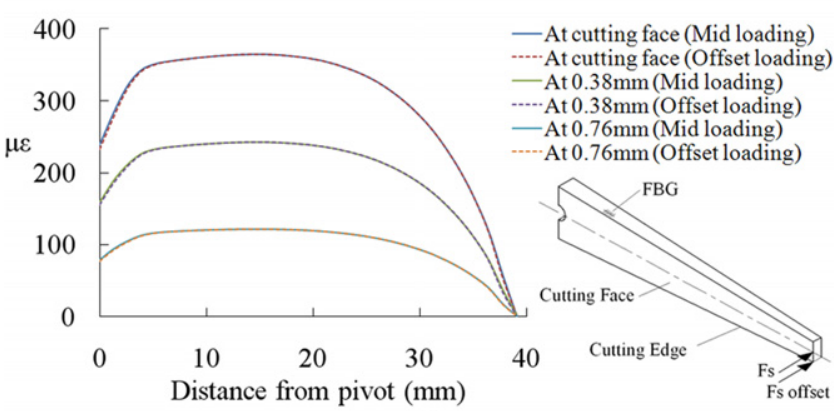

(b)

Figure 2. Strain prof les along the blade top surface when (a) direct loads are applied at the blade neutral axis and offset to the cutting edge and (b) lateral loads are applied at the blade neutral axis and offset to the blade cutting edge.

\subsection{FBG strain sensing}

A single FBG sensor is employed in the solution presented. A f ber Bragg grating comprises of a short section of single-mode optical fber in which the core refractive index is modulated periodically using an intense optical interference pattern [24], typically at UV wavelengths. This periodic index modulated structure enables the light to be coupled from the forward propagating core mode into backward propagating core mode generating a refection response. The wavelength of light ref ected by periodic variations of the refractive index of the Bragg grating, $\lambda_{\mathrm{G}}$, is given by [25],

$$
\lambda_{\mathrm{G}}=2 n_{\mathrm{eff}} \Lambda
$$

where $n_{\text {eff }}$ is the effective refractive index of the core and $\Lambda$ is the periodicity of the refractive index modulation.

The basic principle of operation of any FBG-based sensor system is to monitor the shift in the ref ected wavelength due to changes in measurands such as strain and temperature. The wavelength shift, $\Delta \lambda_{S}$, for the measurement of an applied uniform longitudinal strain, $\Delta \varepsilon$, is given as [25],

$$
\Delta \lambda_{\mathrm{S}}=\lambda_{\mathrm{G}}\left(1-\rho_{\alpha}\right) \Delta \varepsilon
$$

where $\rho_{\alpha}$ is the photo elastic coeff cient of the $\mathrm{f}$ ber.

\subsection{Effects of eccentric loading}

Numerical simulation of eccentric loading was carried out to assess the applicability of employing elementary double tapered beam theory during blade strain analysis. Firstly, the blade was loaded directly $\left(F_{\mathrm{d}}\right)$ at the location of the blade

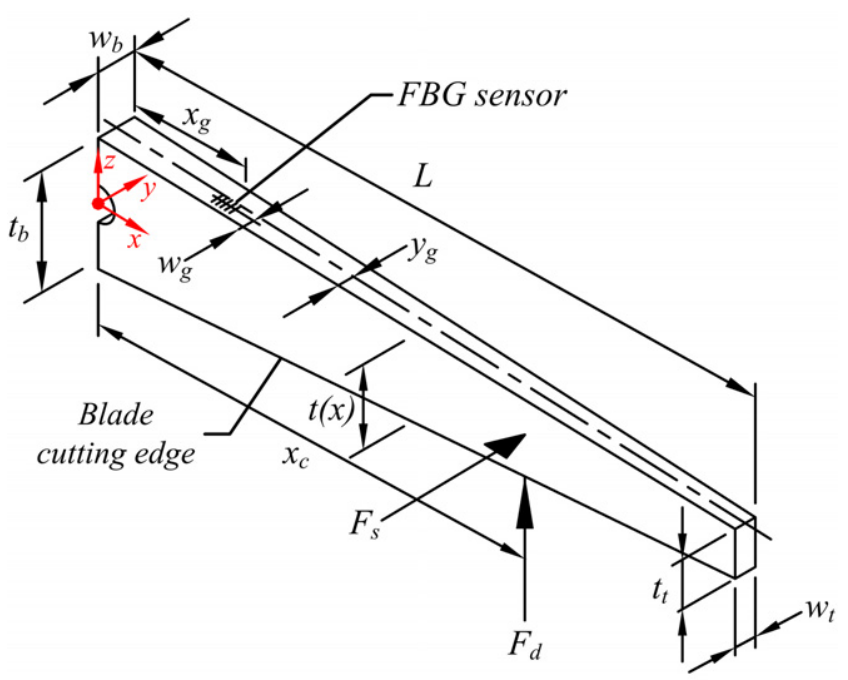

Figure 3. Double tapered scissor blade showing sensor location and orientation of both $F_{\mathrm{s}}$ and $F_{\mathrm{d}}$ generated during blade closing. $F_{\mathrm{d}}$ will act in the opposite direction during blade opening.

neutral axis, then, the load was offset from the neutral axis to the cutting edge. Secondly, a similar evaluation was carried out during lateral loading where $F_{\mathrm{S}}$ was applied at the neutral axis and offset to the cutting edge. $F_{\mathrm{d}}$ and $F_{\mathrm{s}}$ were set to 30 and $10 \mathrm{~N}$ respectively and applied at the blade tip to induce maximum bending moments.

The strain distributions resulting from $F_{\mathrm{d}}$ being applied at the neutral axis, then offset by $0.76 \mathrm{~mm}$ to the blade cutting edge, are shown in f gure 2(a). The strain values were assessed at two locations on the blade upper surface; at the centerline axis (green and purple) and at the cutting face plane (red and blue). Results show that there is no discernible error between the strain plots at these locations under both loading conditions.

During lateral loading, strain distributions were assessed on the blade upper surface at the cutting face plane as well as 0.38 and $0.76 \mathrm{~mm}$ from the cutting face plane (f gure 2(b)). $F_{\mathrm{s}}$ was offset from the neutral axis by $1.345 \mathrm{~mm}$. Analysis of the strain at the three locations found that the impact of eccentric loading induced negligible twisting of the blade. It is reasonable therefore, to assume that the use of elementary beam theory, in which the loads are applied at the blade neutral axis, is representative of a scissor blade being loaded eccentrically along its cutting edge.

\subsection{Tapered blade strain analysis}

The scissor blade onto which an FBG strain sensor is to be attached can be approximated as a cantilever beam tapering uniformly in two planes (f gure 3). The blade is loaded both laterally and directly to investigate the nature of the $2 \mathrm{D}$ strains experienced at the location of the FBG. The FBG sensor is located on the blade upper surface so as not to interfere with blade functionality during opening and closing. Using elementary beam theory, the resultant strain at any location $x$ along the blade length for a given direct force input $F_{\mathrm{d}}$ can be 
estimated from,

$$
\varepsilon(x)=\frac{F_{\mathrm{d}}\left(x_{\mathrm{c}}-x_{\mathrm{g}}\right) t(x)}{2 E I(x)}
$$

where $E$ is the Young's modulus $(210 \mathrm{GPa})$ of the Martensitic stainless steel blade, $x_{\mathrm{c}}$ is the distance from the blade pivot to the point of application of the load and $x_{\mathrm{g}}$ is the distance from the pivot to the center of the FBG sensor. $I(x)$ is the second moment of area of the blade section. The blade thickness, $t(x)$ is represented as,

$$
t(x)=m x+t_{\mathrm{b}}
$$

where $t_{\mathrm{b}}$ is the blade thickness at the pivot. The blade thickness taper ratio, $m$, is def ned as,

$$
m=\left(\frac{t_{\mathrm{t}}-t_{\mathrm{b}}}{L}\right) .
$$

The blade section varies linearly in both planes and consequently the second moment of area $I(x)$ of the section can be expressed as,

$$
I(x)=\frac{\left(n x+w_{\mathrm{b}}\right)\left(m x+t_{\mathrm{b}}\right)^{3}}{12}
$$

where the blade width $w(x)$ is given as,

$$
w(x)=n x+w_{\mathrm{b}}
$$

with the width taper ratio $n$ given as,

$$
n=\left(\frac{w_{\mathrm{t}}-w_{\mathrm{b}}}{L}\right)
$$

Substituting (6) into (3) results in the strain as measured by the FBG at location $x_{\mathrm{g}}$ due to direct loading at $x_{\mathrm{c}}$ and is given as,

$$
\varepsilon_{\mathrm{d}}=\frac{6 F_{\mathrm{d}}\left(x_{\mathrm{c}}-x_{\mathrm{g}}\right)}{E\left(n x_{\mathrm{g}}+w_{\mathrm{b}}\right)\left(m x_{\mathrm{g}}+t_{\mathrm{b}}\right)^{2}} .
$$

Direct force loading of the blade structure during an empty cut arises from frictional contact between the blades during opening and closing. Examination of this empty cut cycle shows that there is effectively a point contact between the two blades at the intersection due to blade curvature in the $x y$ plane. It is therefore reasonable to assume that forces during opening and closing are generated perpendicular to the blade cutting edges at $x_{\mathrm{c}}$. The curved prof le also causes lateral deflec ion creating lateral forces on the blades during a cutting cycle. This lateral deflec ion inf uences the FBG readings as the fber is bonded to the upper surface of the blade. The lateral strain is estimated using an approach analogous to that for calculating the direct strain and is presented as,

$$
\varepsilon_{\mathrm{s}}=\frac{6 F_{\mathrm{s}}\left(x_{\mathrm{c}}-x_{\mathrm{g}}\right)}{E\left(m x_{\mathrm{g}}+t_{\mathrm{b}}\right)\left(n x_{\mathrm{g}}+w_{\mathrm{b}}\right)^{2}} .
$$

However, the f ber lateral location, $y_{\mathrm{g}}$, which can be varied between the blade centerline and blade cutting surface, is according to (10) located at the blade cutting edge where,

$$
y_{\mathrm{g}}=\frac{n x_{\mathrm{g}}+w_{\mathrm{b}}}{2} .
$$

This is an undesirable f ber location as placing the $\mathrm{fber}$ at the blade cutting face interferes with blade functionality as well as compromising the protection of the FBG during operation. The modif cation of (11) to include the term $w_{\mathrm{g}}$ permits the measurement of strain values, at any location between the blade cutting edge and its center axis, to be evaluated according to,

$$
y_{\mathrm{g}}=\frac{\left(n x_{\mathrm{g}}+w_{\mathrm{b}}\right)-2 w_{\mathrm{g}}}{2} .
$$

Substituting (12) into (10) results in equation (13) and describes the lateral strain induced in an FBG strain sensing element attached to the upper surface of a blade. Therefore,

$$
\varepsilon_{\mathrm{s}}=\frac{6 F_{\mathrm{s}}\left(x_{\mathrm{c}}-x_{\mathrm{g}}\right)\left(\left(n x_{\mathrm{g}}+w_{\mathrm{b}}\right)-2 w_{\mathrm{g}}\right)}{E\left(m x_{\mathrm{g}}+t_{\mathrm{b}}\right)\left(n x_{\mathrm{g}}+w_{\mathrm{b}}\right)^{3}}
$$

where $x_{\mathrm{g}}$ and $w_{\mathrm{g}}$ are the longitudinal and lateral locations of the fber on the blade upper surface. The resultant total strain, $\varepsilon$, from the FBG sensing element subjected to both $F_{\mathrm{s}}$ and $F_{\mathrm{d}}$ inputs at coincident locations along the blade length is therefore the sum of $\varepsilon_{\mathrm{d}}$ and $\varepsilon_{\mathrm{s}}$. It is evident that to obtain relevant direct force information perpendicular to the cutting edges, $\varepsilon_{\mathrm{s}}$ needs to be decoupled from the total strain readings.

\subsection{Decoupling strains induced in an FBG during a cutting cycle}

Extracting useful force information from the total FBG strain requires a means of decoupling the $\varepsilon_{\mathrm{s}}$ from $\varepsilon_{\mathrm{d}}$. We propose here that the use of a single FBG on the blades can effectively facilitate the measurement of both $\varepsilon_{\mathrm{s}}$ and $\varepsilon_{\mathrm{d}}$ during operation. This can be achieved by analyzing the total strain measured by the FBG during opening $\left(\varepsilon_{\mathrm{o}}\right)$ and closing $\left(\varepsilon_{\mathrm{c}}\right)$, to allow for the extraction of reliable estimates of $\varepsilon_{\mathrm{s}}$ and $\varepsilon_{\mathrm{d}}$. Note that for a cut without any tissue present between the blades $\varepsilon_{\mathrm{d}}$ becomes $\varepsilon_{\mathrm{f}}$, the strain resulting from blade friction forces only. The strain values measured by the FBG during the closing phase are expressed as,

$$
\varepsilon_{\mathrm{c}}=\varepsilon_{\mathrm{s}}-\varepsilon_{\mathrm{f}}
$$

where $\varepsilon_{\mathrm{f}}$ is negative due to compression on the blade upper surface resulting from friction forces being applied to the blade at $x_{\mathrm{c}}$. During the opening phase the friction force is reversed inducing tension in the blade upper surface, hence,

$$
\varepsilon_{\mathrm{o}}=\varepsilon_{\mathrm{s}}+\varepsilon_{\mathrm{f}}
$$

The inherent lateral curvature of the scissor blades dictates that the blade will defect outward during closing whilst returning to their original shape upon opening. It is reasonable to assume from this that the resultant $\varepsilon_{\mathrm{s}}$, at discrete points along the blade, during opening and closing is equal. Therefore, utilizing equations (14) and (15) results in an expression which estimates $\varepsilon_{\mathrm{f}}$ directly from the total strain measured by the FBG without need for further manipulation, as follows,

$$
\varepsilon_{\mathrm{f}}= \pm \frac{\varepsilon_{\mathrm{o}}-\varepsilon_{\mathrm{c}}}{2}
$$

Expected strain prof les for a cut cycle using typical force values for an empty cut are illustrated in f gure 4 , where the 


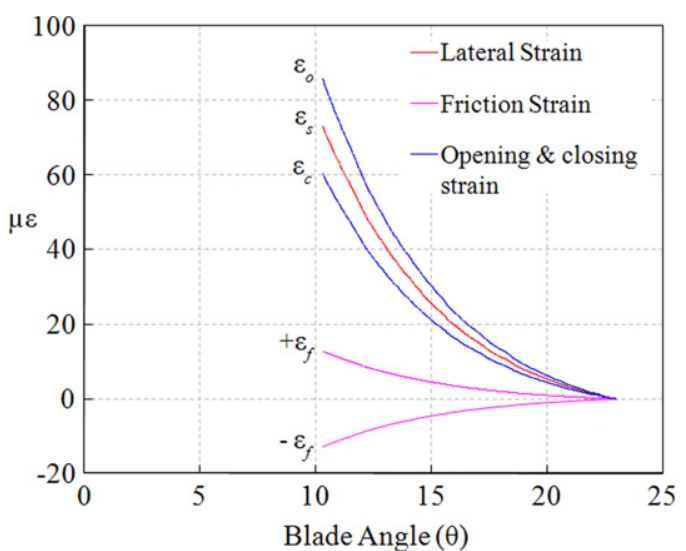

Figure 4. Theoretical lateral, friction and total strain values for an empty pass of the scissor blades during opening and closing phases of the cycle.

blade cutting edge angle $\theta$ is a function of $x_{\mathrm{c}}$ and can be calculated as,

$$
\theta=2 \tan ^{-1}\left(\frac{t_{\mathrm{b}}}{2 x_{\mathrm{c}}}\right) .
$$

This highlights that from a theoretical perspective, accurate $\varepsilon_{\mathrm{f}}$ and $\varepsilon_{\mathrm{s}}$ values can be obtained via a single FBG sensor located on the blade. The resultant strains are proportional to the applied loads and as a result the friction-tolateral strain ratio is def ned as the kinetic friction coeff cient $\mu$.

\subsection{Fracture induced strains}

The strain prof les illustrated in f gure 4 are representative of an empty cut devoid of any material between the blades. However, the cutting of material during the closing phase creates additional compressive effects on the blade upper surface. This further compresses the fi er and reduces the total strain measured by the FBG in proportion to the generated fracture forces. The change in measured strain will allow friction as well as fracture force information to be obtained during cutting (f gure 5). This enables accurate force reflec ion of forces generated at the cutting interface and facilitates the collection of material property data pertaining to the fracture toughness of the materials being cut.

The use of scissor blades is a convenient means of obtaining material fracture toughness by using [26],

$$
J=\frac{W_{\mathrm{ff}}-W_{\mathrm{f}}}{L_{\mathrm{c}} t_{\mathrm{c}}}
$$

where $J$ is the fracture toughness of the material, $W_{\mathrm{ff}}$ is the work done during material cutting, $W_{\mathrm{f}}$ is the work due to blade friction, $L_{\mathrm{c}}$ is the length of the cut and $t_{\mathrm{c}}$ is the thickness of the material being cut. $W_{\mathrm{ff}}$ and $W_{\mathrm{f}}$ are estimated by calculating the areas under their respective force-displacement curves. Subtracting $W_{\mathrm{f}}$ from $W_{\mathrm{ff}}$ results in work done resulting from tissue fracture only,

$$
W=\int_{a}^{b}\left(F_{\mathrm{ff}}-F_{\mathrm{f}}\right) \mathrm{d} z
$$

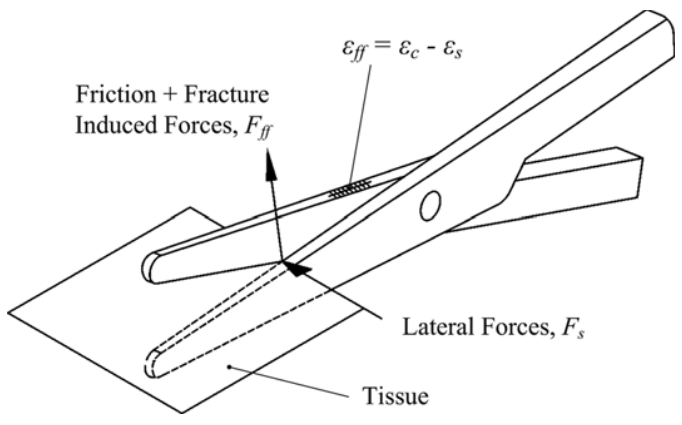

Figure 5. Friction, fracture and lateral forces acting on the scissor blades during the closing phase of a tissue cutting cycle.

where $\mathrm{d} z$ is the inf nitesimal displacement of the scissor actuation mechanism and $b-a$ is the total displacement of this mechanism during a cut. The respective force values are obtained from the decoupled FBG measured strains, $\varepsilon_{\mathrm{ff}}$ and $\varepsilon_{\mathrm{f}}$, which are independent of the inherent lateral strain effects. To obtain strain resulting from tissue cutting, the total FBG strain during closing is modif ed using the following,

$$
\varepsilon_{\mathrm{ff}}=\varepsilon_{\mathrm{c}}-\varepsilon_{\mathrm{s}}
$$

where the $\varepsilon_{\mathrm{s}}$ was found to be constant during both empty and material cutting cycles. Theoretical strain prof les based on the cutting of standard copier paper with a measured fracture toughness of $4.36 \mathrm{~kJ} \mathrm{~m}^{-2}$ are presented in f gure 6 .

The total FBG strain data in f gure 6(a) contains three coupled strain effects, $\varepsilon_{\mathrm{s}} \varepsilon_{\mathrm{ff}}$ and $\varepsilon_{\mathrm{f}}$ resulting from their corresponding force inputs to the blade $F_{\mathrm{s}}, F_{\mathrm{ff}}$ and $F_{\mathrm{f}}$. Since $\varepsilon_{\mathrm{s}}$ is readily ascertained by combining (14) and (15) it can be subtracted from $\varepsilon_{\mathrm{c}}$ to leave strain information pertaining to $F_{\mathrm{ff}}$ over the blade length as shown in f gure 6(c). Comparing $\varepsilon_{\mathrm{ff}}$ in f gure $6(\mathrm{c})$ to $\varepsilon_{\mathrm{f}}$ in f gure 4 , there is approximately a $40 \%$ increase in $\varepsilon_{\mathrm{d}}$ due to the additional forces required to fracture the paper sample.

It should be noted that during the cutting of dry paper samples there is no lubricant present between the blades and as a consequence $F_{\mathrm{f}}$ remains constant throughout the cycle. It is reasonable to assert that the presence of f uids while cutting real tissue may alter the kinetic friction coeff cient compared to dry conditions. However, experiments carried out by [27] on three different types of scissor blades demonstrated that for each pair of scissors, the same friction force readings were obtained during dry and lubricated conditions. The hydrodynamic effects are limited during cutting owing to the low velocities involved as well as a very small contact area between the blades. However, further experiments should be carried out using a range of lubricant types to ascertain the extent to which the friction coeff cient remains constant.

\section{Sensorized blade experimental details}

\subsection{Experimental set-up}

A characterization test-bed has been developed to facilitate the collection of resultant strains as well as the corresponding forces induced during scissor cutting [28]. A standard single mode $125 \mu \mathrm{m}$ diameter FBG sensor (from Smart Fibres Ltd) 


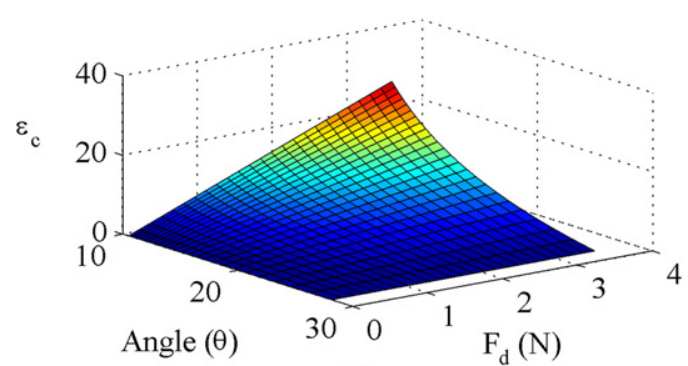

(a)

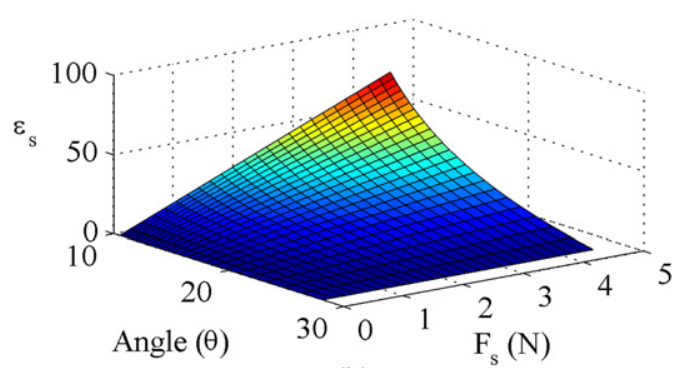

(b)

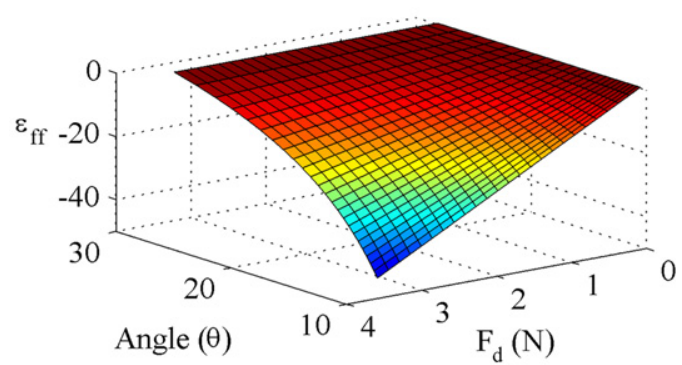

(c)

Figure 6. Theoretical FBG strain characteristics based on typical force values generated during cutting. The total FBG cutting strain is presented in (a) with only the lateral strain values shown in (b). Combined fracture and friction strains over the blade angular range are illustrated in (c).

was bonded to the upper surface of one of the cutting blades. The optical fber used (SMF28) had an acrylate coating of which a $15 \mathrm{~mm}$ portion was removed to allow the $5 \mathrm{~mm}$ FBG to be written into the $\mathrm{f}$ ber core. A polyimide recoat $(4-4.5 \mu \mathrm{m}$ thick), with a stiffness value greater than that of the acrylate, had then been applied over the $15 \mathrm{~mm}$ portion, providing for effective strain transfer. The peak reflec ed wavelength of the FBG was $1550 \mathrm{~nm}$ and the ref ectivity $<70 \%$. The shift in the FBG reflec ed wavelength due to strain is measured using an FBG interrogator (Wx-02) from Smart Fibers Ltd. A load cell (Transducer Techniques ${ }^{\circledR}$ DSM-50) is located proximal to the point of instrument-tissue interaction (f gure 7) to facilitate the measurement of loads applied to the scissors via a pneumatic actuation mechanism. This will allow a direct comparison to be made between force values measured by the FBG and those measured by the proximally located load cell.

It should also be noted that the FBG is sensitive to both strain and temperature. A temperature compensation FBG located on the blade can be used to counteract temperature variation. However, in the present case the internal temperature sensor of the FBG interrogation unit has been used to

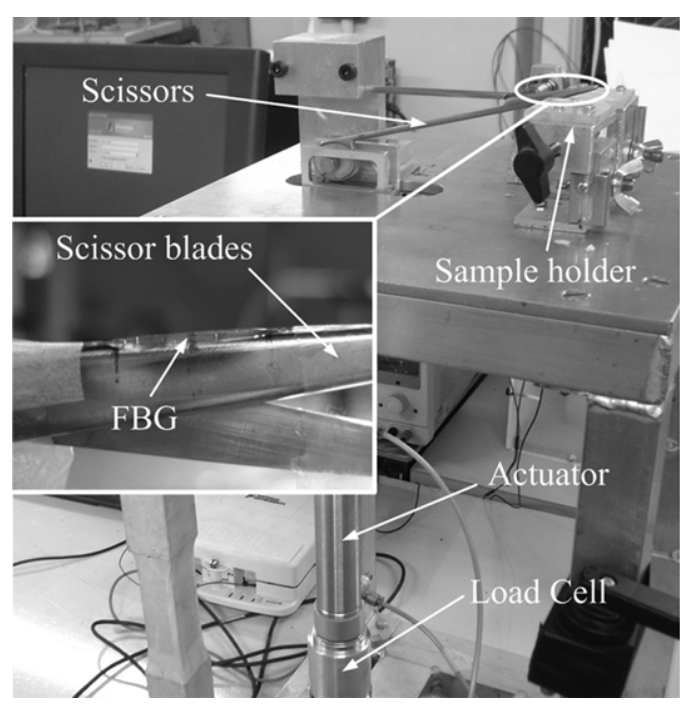

Figure 7. Experimental characterization test-bed showing the location of the FBG.

compensate for the impact of ambient temperature effects on the strain readings. This method of compensation was deemed suitable for the current study as the duration of the cutting cycles are short (approximately $9 \mathrm{~s}$ ) and temperature f uctuation over that duration was minimal. Future work will address this shortcoming by incorporating an FBG temperature sensor into the sensorized instrument resulting in a more accurate sensing device.

\subsection{Sensorized blade calibration}

Calibration of the sensorized scissor blade was carried out over the maximum available cutting range of the scissor blades $\left(25^{\circ}-10.4^{\circ}\right)$. This angular range is a function of linear distance along the blade cutting edge $x_{\mathrm{c}}$ from the pivot to the point of intersection of the blades $(16-39 \mathrm{~mm})$. The calibration procedure involved securing the scissor blades in a clamping fxture and applying a series of static loads at a number of locations along the prescribed cutting envelope. A miniature button load cell was coupled to a micrometer load applicator unit which in turn is connected to a linear precision stage enabling translation of the load cell from blade tip to pivot (f gure 8). Direct loads $F_{\mathrm{d}}$ were applied normal to the blade cutting edge, in $2 \mathrm{~N}$ increments over a $0-30 \mathrm{~N}$ load range, representing direct loading of the blade structure during closing.

The button load cell (SLB-25 from Transducer Techniques) was then translated along the blade cutting edge in $3 \mathrm{~mm}$ increments. The corresponding load cell force readings and strain measured by the FBG were subsequently taken. The relationship between $F_{\mathrm{d}}$ and $\varepsilon_{\mathrm{d}}$ measured by the FBG was found to be linear at each load application point along the blade. The ratio of $F_{\mathrm{d}}$ to $\varepsilon_{\mathrm{d}}$ at location $x_{\mathrm{c}}$ is defi ed as the calibration ratio $R$. This theoretical input-output ratio can be estimated by rearranging (9) such that,

$$
R=\frac{F_{\mathrm{d}}}{\varepsilon_{\mathrm{d}}}=\frac{E\left(n x_{\mathrm{g}}+w_{\mathrm{b}}\right)\left(m x_{\mathrm{g}}+t_{\mathrm{b}}\right)^{2}}{6\left(x_{\mathrm{c}}-x_{\mathrm{g}}\right)} .
$$




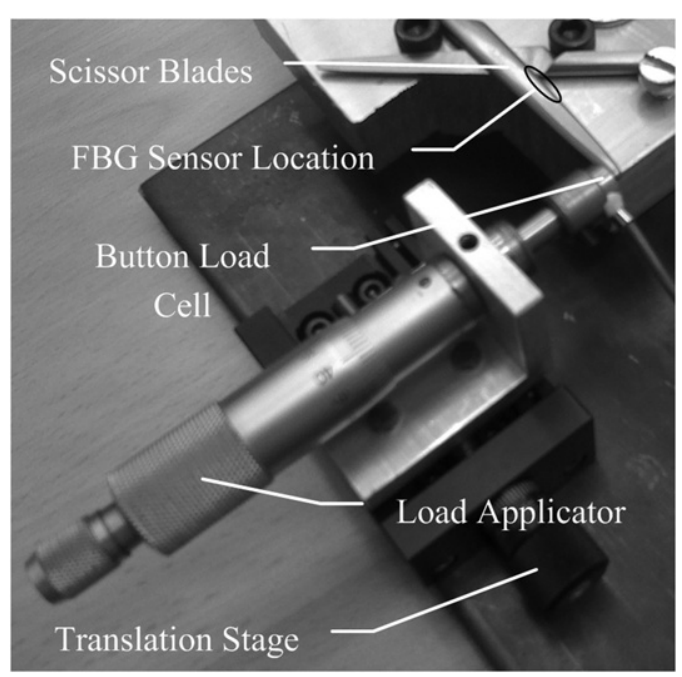

Figure 8. Blade calibration set-up for static direct loading conditions.

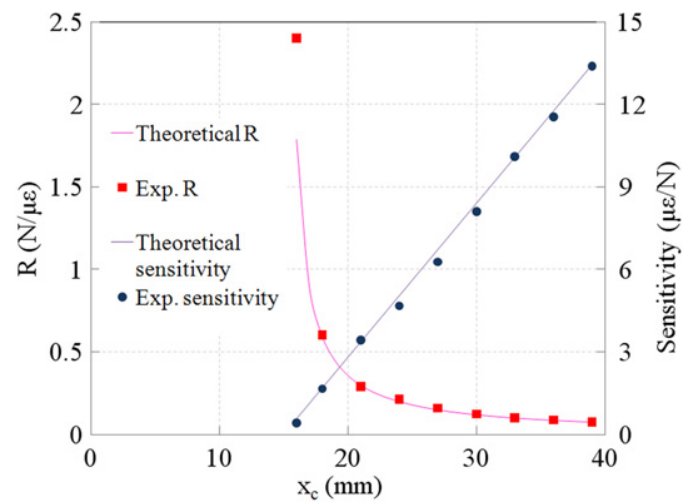

Figure 9. Direct force-strain calibration ratio and blade sensitivity values under direct loading where $x_{\mathrm{c}}$ is the point of load application from the blade pivot.

Experimental values for $R$ and blade sensitivity are plotted along with their respective theoretical values in fi ure 9. A close correlation is obtained, indicating that the representation of the blade as a double cantilever structure is reasonable. It can be seen from these results that the sensitivity of the sensorized blade is high from blade tip to $x_{\mathrm{c}}=20 \mathrm{~mm}$. Thereafter, there is a decrease in blade sensitivity as the applied loads approach the FBG sensor location $\left(x_{\mathrm{c}}=14 \mathrm{~mm}\right)$. Since surgeons typically operate scissors over the $\mathrm{f}$ rst one third of the blade length (26-39 mm) [27] there is little concern about the lower sensitivity beyond this region. However, current research is underway investigating an optimal sensor location which will allow high sensitivity to be extended over a greater length of the blade.

\section{Experimental results}

\subsection{Friction strain}

Initial investigations into the nature of the strains expected from the FBG involved the opening and closing of the blades without any tissue being cut. Friction between the blades is an inherent part of scissor functionality and therefore an

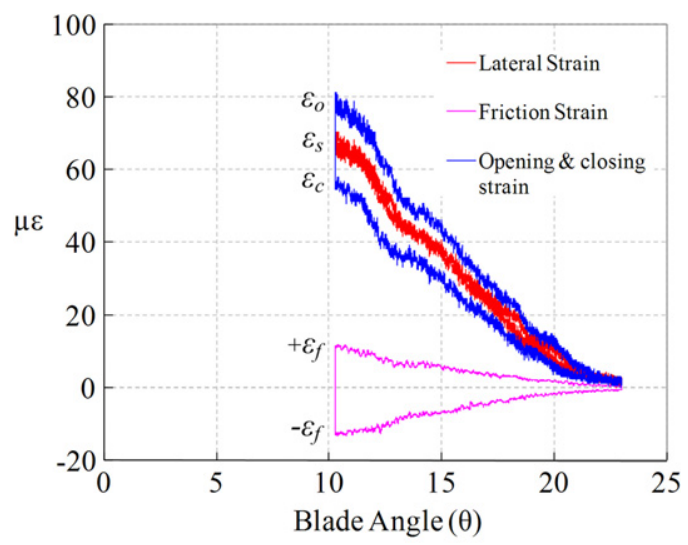

Figure 10. Experimental strain data obtained from a single FBG attached to the scissor blade where, $\varepsilon_{0}$ is the total FBG measured strain during opening, $\varepsilon_{\mathrm{s}}$ is blade lateral strain during both opening and closing, $\varepsilon_{\mathrm{c}}$ is the FBG measured strain during closing, $+\varepsilon_{\mathrm{f}}$ is blade friction during opening and $-\varepsilon_{\mathrm{f}}$ is the blade friction strain during closing.

understanding of how kinetic friction forces contribute to the overall force measurement is required. The blades were secured in the characterization test-bed with opening and closing achieved via pneumatic actuation. Opening and closing rates were kept constant at a rate of $6^{\circ} \mathrm{s}^{-1}$. The $\mathrm{Wx}-$ 02 commercial FBG interrogator unit measured the reflec ed

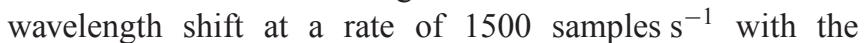
corresponding strain being obtained with a strain sensitivity of $1.2 \mathrm{pm} / \mu \varepsilon$ [25]. The strain results for one complete cycle of the blades are presented in f gure 10. The total strain measured by the FBG (blue) is the sum of both $\varepsilon_{\mathrm{f}}$ and $\varepsilon_{\mathrm{s}}$. The positive and negative $\varepsilon_{\mathrm{f}}$ prof les are extracted by implementing a simple algorithm based on equation (16). Strain values increase toward the end of the cut as expected due to the blade curvature deflec ing the blade laterally. It can be observed from the data presented in f gure 10 that the $\varepsilon_{\mathrm{f}}$ to $\varepsilon_{\mathrm{S}}$ ratio is consistent throughout the cutting cycle. This is the kinetic friction coeff cient between the blades during a dry cutting cycle and was found to be 0.23 for the particular scissor blades used in these experiments.

\subsection{Paper cutting}

A range of cutting experiments were carried out on paper samples to evaluate the performance of the FBG sensor during the cutting cycle. Cuts were carried out within the maximum working envelope of the cutting blades $\left(23^{\circ}-10.4^{\circ}\right)$. Paper samples measuring $100 \times 60 \times 0.1 \mathrm{~mm}$ were securely fi ed between the blades. The total FBG strain (blue) resulting from combined $F_{\mathrm{s}}, F_{\mathrm{ff}}$ and $F_{\mathrm{f}}$ over a complete opening and closing cycle are shown in fgure 11. Analysis shows that there is a distinct decrease in $\varepsilon_{\mathrm{c}}$ during closing resulting from forces required to fracture the paper in front of the blade intersection point. However, this strain decrease is a combination of uncoupled $\varepsilon_{\mathrm{s}}, \varepsilon_{\mathrm{ff}}$ and $\varepsilon_{\mathrm{f}}$. From the perspective of accurate force ref ection to the user and the acquisition of material property data sets, decoupling of the strain components is required. The $\varepsilon_{\mathrm{ff}}$ is obtained by subtracting $\varepsilon_{\mathrm{s}}$, for an empty cut, from $\varepsilon_{\mathrm{c}}$. 


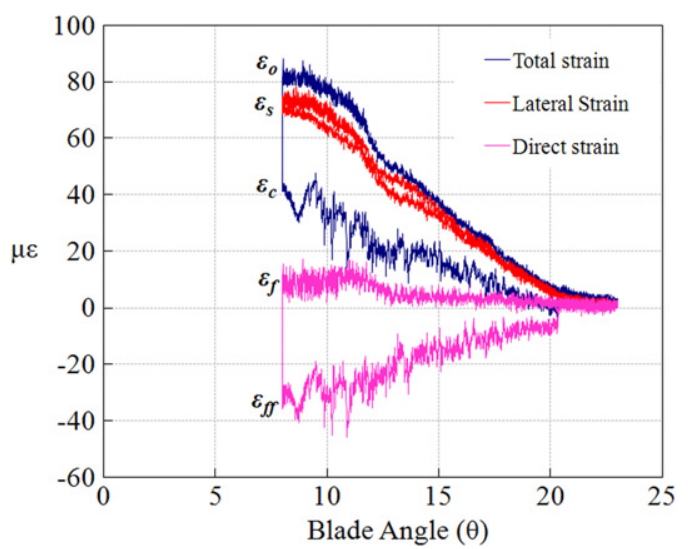

Figure 11. Experimental data obtained from a single FBG during a paper cut where, $\varepsilon_{\mathrm{o}}$ is the total FBG measured strain during opening, $\varepsilon_{\mathrm{s}}$ is the blade lateral strain during opening and closing, $\varepsilon_{\mathrm{c}}$ is the FBG measured strain during cutting (blades closing), $\varepsilon_{\mathrm{f}}$ is the friction strain during blade opening and $\varepsilon_{\mathrm{ff}}$ is the strain resulting from material fracture and friction during closing.

These are the strains reflec ing the forces expected to be felt by the user during cutting due to $F_{\text {ff. }}$.

It was observed during cutting that the cuts made were clean, free from burring and material dragging. These observations, combined with the high blade stiffness, suggest that any additional lateral deflec ion of the blades during paper cutting is negligible compared to that of an empty cut. It is reasonable to assume that a sharp scissor blade cutting a soft tissue will be exposed to negligible lateral def ection in addition to that incurred during empty cuts. Any additional increase in the blade lateral defection and strain would introduce errors into the estimated fracture toughness values. This is due to the fact that accurate strain decoupling requires that the lateral strain remains constant for both empty and tissue cutting cycles.

\subsection{Force measurement validation}

Quantifying the direct forces $F_{\mathrm{d}}$ exerted on the blade is carried out using the calibration equation (21) where $\varepsilon_{\mathrm{d}}$ is the strain as measured by the FBG due to $F_{\mathrm{f}}$ or $F_{\mathrm{ff}}$. Comparing the direct forces measured by the FBG to those measured by the load cell on the test-bed (fi ure 12), it can be seen that there is a close correlation between the two. This shows that the methodology employed of decoupling $\varepsilon_{\mathrm{d}}$ from $\varepsilon_{\mathrm{s}}$ and using the calibration ratio $R$, is an effective means of determining typical cutting characteristics during cutting. It is clear from both force profles that the point at which the blades make initial contact with the paper occurs at approximately $21^{\circ}$. At this point a sudden increase in force from 0.3 to $2 \mathrm{~N}$ is measured as the blades compress the paper sample prior to fracture. From $21^{\circ}$ to $10^{\circ}$ characteristic peaks representing a series of localized compression, deformation and fracture sequences can be observed. The peaks are not present during the opening sequence as no material is being cut but there are fuctuations due to blade frictional contact.

Based on observations of the fuctuation in the measured strain signal (3 $\mu \varepsilon$ approx.) caused by noise in the

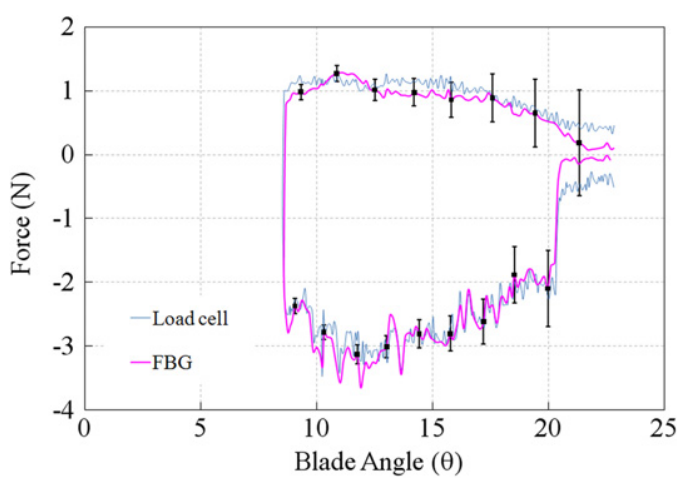

Figure 12. Combined fracture and friction forces acting on the scissor blades obtained using the FBG sensor (pink) and the load cell sensor (blue). Error bars indicate variation in force resolution from the FBG sensor over a full cutting cycle.

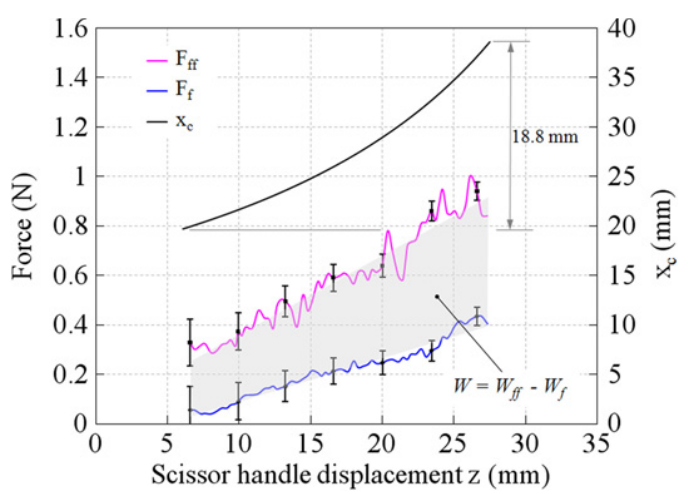

Figure 13. $F_{\mathrm{f}}$ at the scissor handles for an empty cut (blue) and $F_{\mathrm{ff}}$ for a paper sample cut (pink). The variation in $x_{\mathrm{c}}$ as the blades' close is shown enabling the sample cut length to be obtained.

interrogation system, the force resolution over the frst third of the blade was calculated. At $\theta=15^{\circ}$ the resolution is $0.5 \mathrm{~N}$, however, as sensitivity increases toward the blade tip the estimated resolution improves to $0.23 \mathrm{~N}$. The error bars shown in f gure 12 represent the force resolution variation over a complete cutting cycle.

\subsection{Fracture toughness estimation}

$F_{\mathrm{f}}$ and $F_{\mathrm{ff}}$ values at the scissor handles were inferred from the corresponding forces on the blade and used to determine the fracture toughness of the paper samples used. Using (19) the external work done due to combined fracture and friction, $W_{\text {ff }}$, was obtained by integrating under the fracture forcedisplacement profi e in f gure 13. Similarly, the external work done due to friction only, $W_{\mathrm{f}}$, was obtained and subtracted from $W_{\text {ff }}$ resulting in work done due to material fracture only. The cut length, $L_{\mathrm{c}}$, of the sample was acquired by subtracting the distance $x_{\mathrm{c}}$ at the start of the cut from $x_{\mathrm{c}}$ at the end of the cut resulting in a cut length of $18.8 \mathrm{~mm}$. This was verifed by measuring the length of the slit in the sample after cut completion. A fracture toughness value of $4.36 \mathrm{~kJ} \mathrm{~m}^{-2}$ was obtained using (20), comparable to that found in other literature [19]. Error bars are included to convey 
the force resolution, which improves toward the end of the cut as the blades are closed by the scissor handles. These results show that the FBG sensorised instrument is capable of reliably measuring the intrinsic cutting forces and as a result, the fracture toughness of the material can be obtained.

\section{Conclusions}

This paper investigated the application of FBG sensors in the measurement of scissor blade-tissue interaction forces. Sensor placement at the blade-tissue interaction site provides the basis for increased force measurement accuracy, without compromising the functionality of the instrument. This increased accuracy provided the foundation for in-depth analysis of the force components generated during typical scissor cutting cycles. Theoretical analysis and experimental investigation explored the decoupling of the major forces present during cutting. The isolation of tissue-fracture forces from inter-blade friction forces was carried out. This is useful as knowledge of the fracture properties of biological tissues can be diff cult to obtain. Moreover, the force information obtained can be ref ected to the user in a telerobotic application ensuring a greater sense of user immersion. Scissor cutting force data is of particular relevance to those involved in the development of soft tissue models for medical simulation systems.

The motivation behind this work is to develop a smart surgical instrument capable of unobtrusively, and with minimal impact on instrument functionality, detecting tissueinstrument interaction forces. Future work will involve the miniaturization of the current technique enabling the development of a laparoscopic prototype instrument capable of acquiring in vivo force and material fracture properties.

\section{References}

[1] Tholey G, Pillarisetti A and Desai J P 2004 On-site three dimensional force sensing capability in a laparoscopic grasper Ind. Robot. 31 509-18

[2] Kuebler B, Seibold U and Hirzinger G 2005 Development of actuated and sensor integrated forceps for minimally invasive robotic surgery Int. J. Med. Robot. Comp. Assist. Surg. 1 96-107

[3] Berkelman P J, Whitcomb L L, Taylor R H and Jensen P 2003 A miniature microsurgical instrument tip force sensor for enhanced force feedback during robot-assisted manipulation IEEE Trans. Robot. Autom. 19 917-22

[4] Tavakoli M, Patel R V and Moallem M 2005 Haptic interaction in robot-assisted endoscopic surgery: a sensorized end-effector Int. J. Med. Robot. 1 53-63

[5] Mayer H, Gomez F, Wierstra D, Nagy I, Knoll A and Schmidhuber J 2006 A system for robotic heart surgery that learns to tie knots using recurrent neural networks IEEE Int. Conf. on Intelligent Robots and Systems (Beijing) (Piscataway, NJ: IEEE) pp 543-8

[6] Prasad S K, Kitagawa M, Fischer G S, Zand J, Talamini M A, Taylor R H and Okamura A M 2003 A modular 2-DOF force-sensing instrument for laparoscopic surgery Lecture Notes in Computer Science vol 2879 (Heidelberg: Springer) pp 279-86

[7] Tholey G and Desai J P 2007 A modular, automated laparoscopic grasper with three-dimensional force measurement capability Proc. IEEE Int. Conf. on Robotics and Automation (Rome) (Piscataway, NJ: IEEE) pp 250-5
[8] Saha A 2006 Appropriate degrees of freedom of force sensing in robot-assisted minimally invasive surgery $M S c$ Dissertation Johns Hopkins University

[9] Puangmali P, Althoefer K, Seneviratne L D, Murphy D and Dasgupta P 2008 State-of-the-art in force and tactile sensing for minimally invasive surgery IEEE Sensors $J .8371-80$

[10] Tholey G, Pillarisetti A, Green W and Desai J P 2004 Medical Simulation pp 38-48

[11] Trejos A L, Patel R V and Naish M D 2009 Force sensing and its application in minimally invasive surgery and therapy: a survey Proc. Inst. Mech. Eng. C 224 1435-53

[12] Wroblewska A 2005 Methods of the force measurement for robotic surgical tools robot motion and control RoMoCo '05: Pro. 5th Int. Workshop on Robot Motion and Control pp 51-4

[13] Ascari L, Corradi P, Beccai L and Laschi C 2007 A miniaturized and f exible optoelectronic sensing system for tactile skin J. Micromech. Microeng. 172288

[14] Sutherland G R, McBeth P B and Louw D F 2003 NeuroArm: an MR compatible robot for microsurgery Int. Cong. Ser. $1256504-8$

[15] Mueller M S, Hoffmann L, Christopher Buck T and Walter Koch A 2009 Fiber Bragg grating-based force-torque sensor with six degrees of freedom Int. J. Optomech. 3 201-14

[16] Iordachita I, Sun Z, Balicki M, Kang J, Phee S, Handa J, Gehlbach P and Taylor R 2009 A sub-millimetric, $0.25 \mathrm{mN}$ resolution fully integrated f ber-optic force-sensing tool for retinal microsurgery Int. J. Comput. Assist. Radiol. Surg. 4 383-90

[17] Yong-Lae P, Elayaperumal S, Daniel B, Seok Chang R, Mihye S, Savall J, Black R J, Moslehi B and Cutkosky M R 2010 Real-time estimation of 3-D needle shape and deflec ion for MRI-guided interventions IEEE/ASME Trans. Mechatron. 15 906-15

[18] Ragavendra N, Ju J, Sayre J, Hirschowitz S, Chopra I and Yeh M 2008 In vivo analysis of fracture toughness of thyroid gland tumors J. Biol. Eng. 212

[19] Mahvash M, Voo L M, Diana K, Jeung K, Wainer J and Okamura A M 2008 Modeling the forces of cutting with scissors IEEE Trans. Biomed. Eng. 55 848-56

[20] Okamura A M, Webster R J III, Nolin J T, Johnson K W and Jafry H 2003 The haptic scissors: cutting in virtual environments Robotics and Automation 2003 Proc. ICRA '03. IEEE Int. Conf. on Taipei vol 1, pp 828-33

[21] Chial V B, Greenish S and Okamura A M 2002 On the display of haptic recordings for cutting biological tissues HAPTICS 2002. Proc. 10th Symp. on Haptic Interfaces for Virtual Environment and Teleoperator Systems pp 80-7

[22] Azar T and Hayward V 2008 Estimation of the fracture toughness of soft tissue from needle insertion Proc. 4th Int. Symp. on Biomedical Simulation (London: Springer)

[23] Kruzic J J, Kim D K, Koester K J and Ritchie R O 2009 Indentation techniques for evaluating the fracture toughness of biomaterials and hard tissues J. Mech. Behav. Biomed. Mater. 2 384-95

[24] Hill K O and Meltz G 1997 Fiber Bragg grating technology fundamentals and overview J. Lightwave Technol. $151263-76$

[25] Rao Y-J 1997 In-fibr Bragg grating sensors Meas. Sci. Technol. $8355-75$

[26] Pereira B P, Lucas P W and Swee-Hin T 1997 Ranking the fracture toughness of thin mammalian soft tissues using the scissors cutting test J. Biomech. 30 91-4

[27] Greenish S, Hayward V, Chial V, Okamura A M and Steffen T 2002 Measurement, analysis and display of haptic signals during surgical cutting Presence: Teleoper. Virtual Environ. 11 626-51

[28] Callaghan D J, McGrath M M and Coyle E 2007 A force measurement evaluation tool for telerobotic cutting applications: development of an effective characterization platform Int. J. Eng. Appl. Sci. 3 362-8 


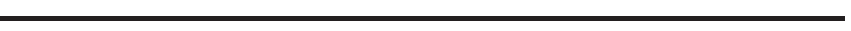

